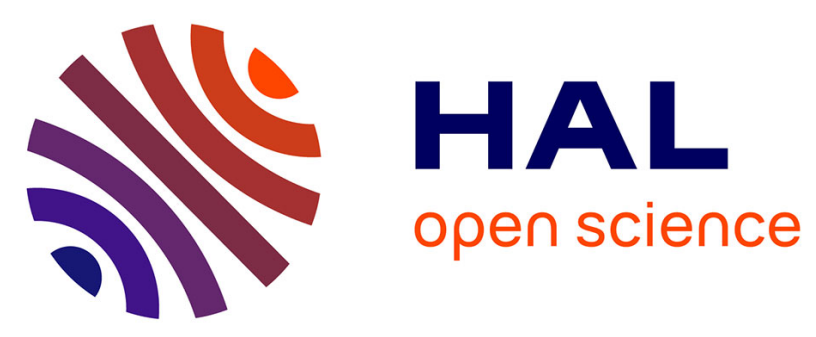

\title{
Comparison of falling dart and Charpy impacts performances of compatibilized and not compatibilized polypropylene/woven glass fibres composites
}

\author{
G. Simeoli, L. Sorrentino, F. Touchard, D. Mellier, M. Oliviero, P. Russo
}

\section{- To cite this version:}

G. Simeoli, L. Sorrentino, F. Touchard, D. Mellier, M. Oliviero, et al.. Comparison of falling dart and Charpy impacts performances of compatibilized and not compatibilized polypropylene/woven glass fibres composites. Composites Part B: Engineering, 2019, 165, pp.102-108. 10.1016/j.compositesb.2018.11.090 . hal-03026240

\author{
HAL Id: hal-03026240 \\ https://hal.science/hal-03026240
}

Submitted on 26 Nov 2020

HAL is a multi-disciplinary open access archive for the deposit and dissemination of scientific research documents, whether they are published or not. The documents may come from teaching and research institutions in France or abroad, or from public or private research centers.
L'archive ouverte pluridisciplinaire HAL, est destinée au dépôt et à la diffusion de documents scientifiques de niveau recherche, publiés ou non, émanant des établissements d'enseignement et de recherche français ou étrangers, des laboratoires publics ou privés. 


\title{
Comparison of falling dart and Charpy impacts performances of compatibilized and not compatibilized polypropylene/woven glass fibres composites
}

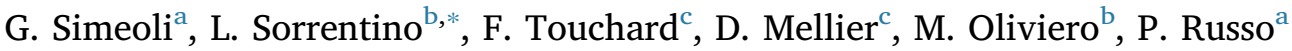 \\ ${ }^{a}$ Institute for Polymers, Composites and Biomaterials, National Research Council, Via Campi Flegrei 54, 80078, Pozzuoli, NA, Italy \\ ${ }^{\mathrm{b}}$ Institute for Polymers, Composites and Biomaterials, National Research Council, Piazzale E. Fermi 1, 80055, Portici, NA, Italy \\ ${ }^{\mathrm{c}}$ PPRIME Institute, CNRS-ISAE-ENSMA-University of Poitiers, 1 Av. Clement Ader, B.P. 40109, 86961, Futuroscope, France
}

Keywords:

Thermoplastic composites

Interface strength

Glass fibres

Falling dart impact

Charpy impact

\begin{abstract}
A B S T R A C T
The effect of the matrix/fibre interface strength on the in-plane and out-of-plane impact performances of glass woven fabric/polypropylene laminates, prepared by means of film stacking technique, was investigated. The interface strength between polymer and fibres was varied by means of a coupling agent added to two different polypropylene grades in order to evaluate its contribution to the impact resistance of the laminates. The static characterization showed that the flexural strength of compatibilized laminates was higher with respect to that of composites based on neat matrices. On the contrary, composites with low interface strength between fibres and polymer showed a strong improvement in impact resistance, in both Charpy and falling dart impact tests. This was related to the possibility of fibres to slip into the matrix and dissipate energy through friction, and to the improved capability to bear load before fibre failure, allowed by the limited propagation of cracks through the laminate. The damage after impact was assessed by means of micro-computed tomography, which elucidated the role of the weak matrix/fibre interface in improving the impact resistance.
\end{abstract}

\section{Introduction}

Thermoplastic composites are ever more expanding their use in many engineering applications ranging from aerospace to automotive and marine fields, from defence to sporting industries owing to their several peculiarities such as high vibration dampening, lightness, longer shelf life and shorter processing times with respect to thermoset based ones, recyclability, high durability in terms of superior fatigue characteristics, non-abrasiveness, toughness and good corrosion resistance [1-3]. Composite structures, during manufacture, normal operations, maintenance and so on, are susceptible to low energy impacts by foreign objects, thus their behaviour under impact loading is one of the major concerns to verify their suitability for potential applications $[4,5]$.

Among all thermoplastic composites, polypropylene (PP) based systems are widely investigated because of the very high performance/ cost ratio and the high specific properties [4-6]. PP is broadly used in industrial applications due to its high chemical and wear resistance, easy processability, low cost and excellent specific mechanical properties. In the same fashion, glass fibres among reinforcing fibres are characterized by low cost, high tensile strength and high chemical resistance. Their use in PP based composites is challenging because the adhesion with PP is weak due to the very different polarity of the two species (polar molecular structure in the glass and non-polar in the polypropylene) and compatibilizing agents are conventionally considered mandatory for the production of PP/glass fibres laminates. Russo et al. [7] studied the influence of the compatibilizer content on the flexural and low velocity impact properties of polypropylene based laminates reinforced with woven glass fibres. The results demonstrated that the presence of maleated polypropylene as compatilizer significantly increases the capability of the load transfer between the matrix and the embedded reinforcing fibres and, consequently, the bending performances (flexural modulus and strength). However, a reduction in laminate toughness for compatibilized systems was regularly measured, and it was in direct relation with the compatibilizer content. Recently a new approach (named IGIS from Interlaminar Graded Interface Strength) has been proposed as a hybridization technique that exploits large interface strength differences between matrix and reinforcement [7-10]. The analysis of the low velocity impact behaviour of IGIS composites based on PP and glass fibre fabrics showed 
that a strong interface strength reduces the energy absorption capabilities of the laminate while the proper positioning of polymeric layers with a low fibre/matrix adhesion strongly improves the low velocity impact damage tolerance while keeping high the static mechanical response [11].

The impact behaviour of composites is largely investigated through the analysis of out-of-plane (OOP) response through falling dart machines but in-plane behaviour is also important to understand the capability of the system to bear complex (not perpendicular) impact loads and to allow their correct modelling. This can be carried out by means of the Charpy impact test, which is widely used for the investigation of both unreinforced and reinforced plastics [12,13] and consists in subjecting a specimen to a three-point flexural tests by a swinging instrumented pendulum. However, it is difficult to relate the absorbed energy of a specimen to that of an actual structural component given their complex failure mode combining different mechanisms as delamination, fibre debonding, fibre breaking and so on. Russo et al. [14] investigated the effect of the coupling agent on the mechanical behaviour of jute fibres/polypropylene composites. The authors showed that the inclusion of the compatibilizer increases the impact initiation energy and Charpy breaking load. Rahman et al. [15] reported on the effect of specimen size and geometry, fibre loading and test temperature on the Charpy impact of glass fibres/polypropylene composites. In particular, in terms of peak load and fracture energy, results showed that the first impact parameter increases with the fibre loading and the specimen size/geometry but decreases with the increasing of the test temperature. The fracture energy, instead, increases with both the test temperature and the specimen size/geometry but it decreases with the fibre content up to a plateau value. Despite the interesting information that can be obtained by means of the Charpy impact test on composite materials, the scientific literature focuses on the potential damage induced in laminates by low-velocity impact events that might occur during their manufacture, service, and maintenance. For this reason, most of the efforts are spent to investigate the out of plane impact in composite systems through the falling dart impact testing machine [16-18].

In order to analyze damages induced by impacts in composites, $\mathrm{X}$ ray micro-computed tomography (micro-CT) emerged as a very effective non-destructive $3 \mathrm{D}$ visualization technique for materials and composites characterization [19]. It is based on the measurement of the attenuation of X-ray photons. When incident photons pass through an object, their attenuation will depend on the physical density of the matter. Contrast arises because different phases (and/or defects) have different levels of X-ray attenuation [20]. For composites, it is particularly useful for studying internal damages, including delamination and microcracking [21]. The capability of such technique of showing the consequences of fibre/polymer interface strength gradation on the impact properties of fabric reinforced laminates was proved in Ref. [22], where the authors used the microCT analysis to detect and visualize the damages induced by a low velocity OOP impact. MicroCT analysis was never used to investigate the effects of damages in composites after impacts performed with the Charpy pendulum, to the best of authors knowledge.

In this contribution, the impact behaviour of polypropylene/woven glass fabric composites was investigated by means of both falling dart and Charpy impact testing techniques to show the role of the interface strength on the impact resistance along in-plane and out-of-plane directions. This research investigated also the effects of the use of a compatibilizer on the mechanical behaviour of laminates based on two grades of polypropylene, differing for their viscosity and crystallinity, and glass fibre fabrics, assembled with a $0^{\circ} / 90^{\circ}$ configuration.

\section{Experimental}

\subsection{Materials}

Two different polypropylene grades, Moplen EP348U (melt flow index MFI@230 ${ }^{\circ} \mathrm{C} / 2.16 \mathrm{Kg}=70 \mathrm{~g} / 10 \mathrm{~min}$ ), supplied by Lyondell Basell Industries (Italy), and Mosten MA712 (melt flow index MFI@ $230{ }^{\circ} \mathrm{C} / 2.16 \mathrm{Kg}=12 \mathrm{~g} / 10 \mathrm{~min}$ ), supplied by Unipetrol (Czech Republic) were used as matrices for the preparation of glass fibre reinforced composites. They were coded as LV and HV, respectively. Polypropylene grafted with maleic anhydride (PP-g-MA) commercialized under the trade name Polybond 3200 (MFI $115 \mathrm{~g} / 10 \mathrm{~min}, 1 \mathrm{wt} \%$ maleic anhydride; from Chemtura, Philadelphia - PA, USA) was added to both polypropylene resins as a coupling agent in a quantity of $2 \%$ by weight in order to enhance the adhesion of the polymer with the reinforcing fibres in the composite laminates. Compatibilized matrices were identified by adding the suffix "- PB" to the matrix code. The woven glass fabric was a plain weave type (E-type glass fibres) with a specific mass of $204 \mathrm{~g} / \mathrm{m}^{2}$. The fabric was functionalized by means of amino-silane groups. Composites were identified by prefixing " $\mathrm{C}-$ " to the matrix code. A summary of the main characteristics of the laminates is reported in Table 1, along with the performed tests for each sample.

\subsection{Sample preparation}

The laminates were prepared by using the film stacking technique, consisting in alternating films of polymer and fabrics. Films with a thickness equal to $35-40 \mu \mathrm{m}$ were prepared by using a film blowing extrusion line (model Teach-Line E $20 \mathrm{~T}$ from Collin Gmbh, Ebersberg Germany). A compression moulding machine (model P300P, Collin $\mathrm{GmbH}$, Ebersberg, Germany) was used to produce composite laminates according to a specific moulding cycle, pre-optimized on the basis of the viscosity of the two PP grades (see Fig. 1). Specifically, laminates consisting of 20 balanced fabric layers $0^{\circ} / 90^{\circ}$, symmetrically arranged with respect to the middle plane of the laminate $\left(\left[(0 / 90)_{10}\right]_{s}\right.$ configuration), were obtained with a target thickness of $3.0 \mathrm{~mm}$ and glass fibre content of $50 \%$ by volume. Volume percentage of fibre and matrix, density and void content were evaluated according to ASTM D 3171-99. In particular, the fibre volume content ranged between $53.5 \%$ and $55.0 \%$ and, hence, the reinforcement content was considered constant among the laminates for the sake of the applied characterizations.

All the laminates were found to be free of voids and well compacted, as witnessed by optical as well as SEM analyses performed on at least 5 observations for each sample (the analysis is not shown for brevity but details can be found in Ref. [9]). Furthermore, the effectiveness of the processing conditions in impregnating the laminates was also confirmed by the microCT analysis, which has never shown the presence of voids.

Table 1

Main characteristics of laminates and characterization plan.

\begin{tabular}{|c|c|c|c|c|c|c|}
\hline Laminate code & Polymer & Compatibilizer & Bending test & \multicolumn{3}{|c|}{ Impact test } \\
\hline $\mathrm{C}-\mathrm{LV}$ & Moplen EP348U & & $\mathrm{x}$ & $\mathrm{X}$ & & $\mathrm{x}$ \\
\hline $\mathrm{C}-\mathrm{HV}$ & Mosten MA712 & & $\mathrm{x}$ & $\mathrm{x}$ & $\mathrm{x}$ & $\mathrm{x}$ \\
\hline $\mathrm{C}-\mathrm{HV}-\mathrm{PB}$ & Mosten MA712 & $\mathrm{x}$ & $\mathrm{x}$ & $\mathrm{X}$ & $\mathrm{x}$ & $\mathrm{x}$ \\
\hline
\end{tabular}



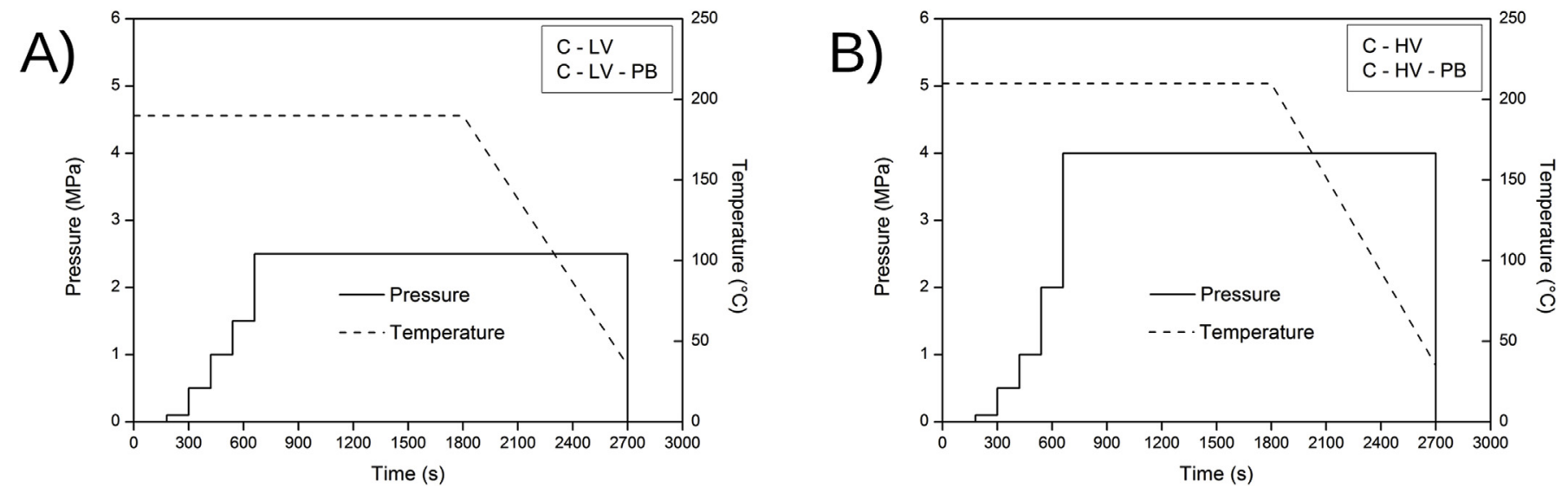

Fig. 1. Operative conditions of compression moulding stage to prepare composite laminates.

\subsection{Characterization techniques}

Flexural properties were carried out by means of a three point bending configuration set according to the ASTM D 790-10, using a universal testing machine (mod. 3360 from Instron Inc., Akron - OH, USA) equipped with a $5 \mathrm{kN}$ load cell. Composite specimens $100 \mathrm{~mm} \times 10 \mathrm{~mm}$ (length $\mathrm{x}$ width) in size were cut from plates and tested after setting the displacement rate at $1.28 \mathrm{~mm} / \mathrm{min}$. In all cases, the span to thickness ratio was $16: 1$, with a span of $48 \mathrm{~mm}$.

Flexural modulus $\left(E_{F}\right)$ and flexural strength $\left(\sigma_{F}\right)$ were evaluated from engineering stress-strain curves, and their values and variance were calculated from at least five tests for each investigated sample.

Two different impact tests were carried out to evaluate the laminate performance in out-of-plane and in-plane impacts (Fig. 2). Out-of-plane impact tests were conducted using an instrumented drop-weight impact testing machine (model Fractovis Plus from CEAST - Italy) equipped with a hemispherical tip (diameter $12.7 \mathrm{~mm}$ ). All tests were performed putting the specimen on a stainless steel annular ring (internal diameter $40 \mathrm{~mm}$, outer diameter $60 \mathrm{~mm}$ ). Two impact energy values were used for the falling dart impact, namely $27 \mathrm{~J}$ and $105 \mathrm{~J}$. Some preliminary perforation tests indicated $105 \mathrm{~J}$ as the energy capable of perforating all composite configurations. An impact energy value equal to $27 \mathrm{~J}$ was used to compare not perforated laminates. Such value was slightly lower than the absorbed energy at the load peak of the C-LV-PB laminate during the $105 \mathrm{~J}$ impact. This criterion was used because $27 \mathrm{~J}$ was estimated to be the impact energy capable of inducing the largest damage possible to the composite structure without incurring in its perforation. Such procedure allowed the direct comparison of compatibilized and not compatibilized laminates under severe impact conditions. For each composition, at least four specimens measuring $80 \mathrm{~mm} \times 80 \mathrm{~mm}$ and cut from the prepared plates, were tested and results are reported in terms of their mean values and variance. Charpy

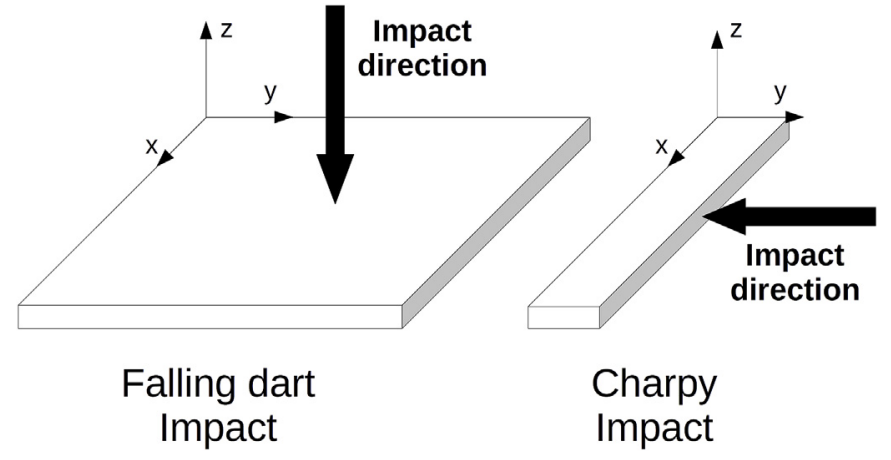

Fig. 2. Impact directions in falling dart and Charpy impact tests. impact tests have been performed by an instrumented pendulum (model 6545 from CEAST, Italy) with a mass of $7.31 \mathrm{Kg}$ and setting an impact velocity of $2.71 \mathrm{~m} / \mathrm{s}$ in order to have an impact energy approximately equal to $27 \mathrm{~J}$. Specimens were cut from plates $80 \mathrm{~mm} \times 10 \mathrm{~mm}$ in size, and the support span was $60 \mathrm{~mm}$ (20:1 span/ thickness ratio). For each system at least five unnotched specimens were considered and average results were collected.

Optical analysis in reflection mode was carried out by using a microscope (BX51 from Olympus, Japan) to investigate the fibres impregnation in the composite. Fractured surfaces were analysed by a field emission scanning electron microscope, model QUANTA-200FEG from FEI (Eindhoven, The Nederlands). The examined surfaces were coated with a thin layer of a gold-palladium alloy prior to SEM analysis. All glass fibre composite samples were prepared by polishing the observation surfaces with wet sandpaper and then with a very fine polishing paste.

Microtomographic image acquisition has been performed using an UltraTom CT scanner manufactured by RX Solutions (France). The system consists in a Hamamatsu micro focus sealed X-ray tube operating at $20-150 \mathrm{kV} / 0-500 \mu \mathrm{A}$, within a maximum power of $75 \mathrm{~W}$. A precision object manipulator has been used for positioning and rotating the sample during the acquisition of tomographic data. The divercenge of X-rays generated by the source (cone beam) provides the possibility to magnify the sample by playing with the sample position with respect to the generator and/or the detector, both also movable to cover a large range of magnifications. A $16 \mu \mathrm{m}$ resolution has been used for the acquisitions in this work, with an accelerating voltage of $70 \mathrm{kV}$ and a beam current of $428 \mu \mathrm{A}$. The flat panel detector, consisting in an X-ray CsI scintillator screen settled on an amorphous silicon layer, has $1920 \times 1536$ pixels with a pixel size of $127 \mu \mathrm{m}$. The X-ray shadow projections are digitized with 65536 brightness gradations ( 16 bits) and recorded in TIFF image format. The image acquisition time was about $2 \mathrm{~h}$ per specimen. For 3D reconstruction, X-ray images were acquired from 1440 rotation views over $360^{\circ}$ of rotation $\left(0.25^{\circ}\right.$ rotation step). The reconstruction was performed using an algorithm based on the filtered back-projection procedure for Feldkamp cone beam geometry.

\section{Results and discussion}

\subsection{Static characterization}

Table 2 summarizes the average values of flexural modulus and flexural strength of investigated composites. The addition of the compatibilizing agent had a significant effect on the mechanical performance of fibre reinforced laminates. In compatibilized systems (C-LV$\mathrm{PB}$ and $\mathrm{C}-\mathrm{HV}-\mathrm{PB}$ ) flexural modulus and flexural strength were higher than in the case of not compatibilized ones (C-LV and C-HV) due to the stronger interface strength between polymer and fibres. Albeit the 
Table 2

Main parameters from bending tests evaluated on composites.

\begin{tabular}{llllll}
\hline Sample & $\begin{array}{l}\text { Density } \\
\left(\mathrm{g} / \mathrm{cm}^{3}\right)\end{array}$ & $V_{f}(\%)$ & $\begin{array}{l}\text { Flexural } \\
\text { Modulus } \\
(\mathrm{GPa})\end{array}$ & $\begin{array}{l}\text { Flexural } \\
\text { Strength } \\
(\mathrm{MPa})\end{array}$ & $\begin{array}{l}\text { Strain at yield } \\
(\%)\end{array}$ \\
\hline $\mathrm{C}-\mathrm{LV}$ & 1.78 & 53.5 & $15.1 \pm 0.32$ & $112 \pm 3.3$ & $1.07 \pm 0.03$ \\
$\mathrm{C}-\mathrm{LV}-\mathrm{PB}$ & 1.80 & 55.0 & $16.5 \pm 0.27$ & $164 \pm 3.8$ & $1.31 \pm 0.09$ \\
\hline C - HV & 1.78 & 53.7 & $15.3 \pm 0.21$ & $97.9 \pm 4.8$ & $0.84 \pm 0.05$ \\
C - HV - PB & 1.79 & 54.1 & $17.1 \pm 0.33$ & $183 \pm 3.4$ & $1.49 \pm 0.23$ \\
\hline
\end{tabular}

increase in flexural modulus was limited $(+9.2 \%$ for C-LV-PB and + $11.8 \%$ for C-HV-PB with respect to C-LV and C-HV, respectively), the strong fibre/polymer interface resulted in a marked advantage in the flexural strength $(+46 \%$ for C-LV-PB and $+87 \%$ for C-HV-PB with respect to $\mathrm{C}-\mathrm{LV}$ and $\mathrm{C}-\mathrm{HV}$, respectively). The reduced interface strength seems to cap the flexural modulus, because C-LV ad C-HV showed very similar values. These results agree with those reported in literature for similar systems by Thomason [23] and can be explained by considering that a stronger interface allows a more efficient load transfer between matrix and fibres thus reducing the strain under the same applied stress.

\subsection{Impact characterization - out of plane impacts}

Fig. 3A shows the comparison of typical load/deflection and absorbed energy/deflection curves from impacts at $105 \mathrm{~J}$, while Table 3 summarizes the main impact parameters calculated from them. The initial slope (at deflection lower than $5 \mathrm{~mm}$ ) of such curves is directly related to the static stiffness (flexural modulus) of laminates. In this regime the deformation of the laminate didn't induce any significant fibre related or matrix related failure and the inclusion of PP-g-MA helped in reducing the deformation at constant load. In fact, looking at each load value, the deflection of compatibilized laminates is lower than in not compatibilized ones. For deflections higher than $5 \mathrm{~mm}$, the curves of compatibilized systems show a peak, due to the occurrence of marked damages in the laminate mainly due to fibre breakage. The sudden drop in load during the impact occurred in inverse relation with the flexural strength of laminates. In fact, the first collapsing laminate was the strongest according to the static behaviour (C-HV-PB), followed by C-LV-PB, C-LV and C-HV. Perforation occurred under significantly higher loads in C-LV (at $9734 \mathrm{~N}$ ) compared to C-LV-PB (at $8554 \mathrm{~N}$, $-12.1 \%$ ) and C-HV (at $13217 \mathrm{~N}$ ) with respect to C-HV-PB (at $7497 \mathrm{~N}$, $-43.3 \%)$. Simultaneous higher loads and higher deflections at perforation were responsible for the strong increase in absorbed energy at load peak in not-compatibilized systems with respect to compatibilized ones $(+28 \%$ for $\mathrm{LV}$ and $+140 \%$ for HV systems). The capability of laminates with poor fibres/matrix adhesion to bear higher loads is confirmed by load/absorbed energy curves in Fig. 3B, where the energy absorbed by laminates during the increase of the load is shown. Laminates with a strong interface between matrix and fibres reach the load peak at a lower absorbed energy with respect to laminates with low interface strength.
A

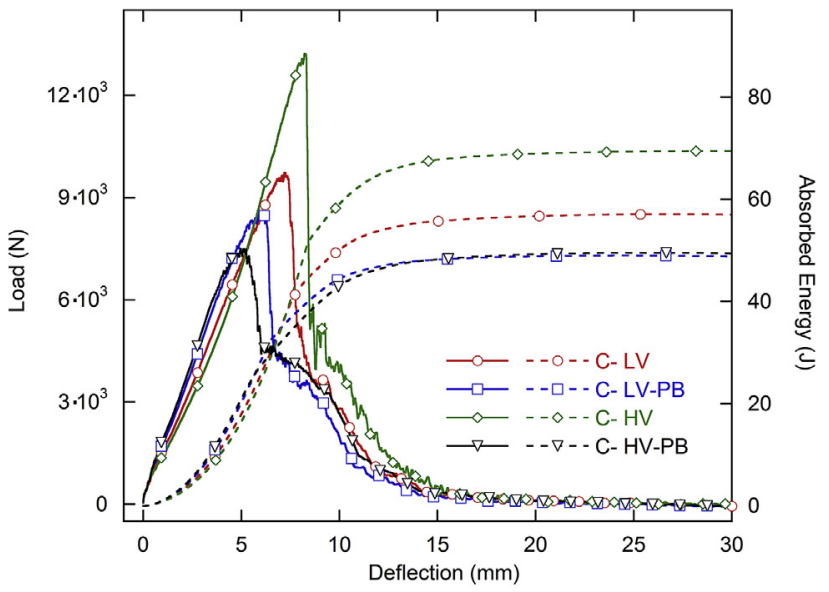

B

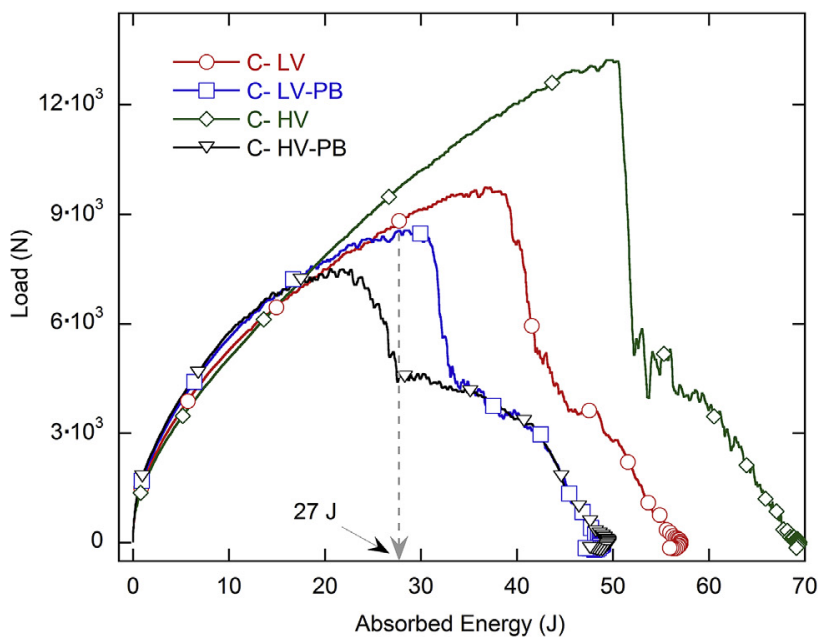

Fig. 3. Characteristic curves of laminates from penetration tests at $105 \mathrm{~J}$ : A) Load-Deflection and Absorbed Energy-Deflection, B) Load-Absorbed Energy.

In order to better understand how the low interface strength helps in increasing the perforation threshold, a non perforating impact event, at $E_{i}=27 \mathrm{~J}$, was performed on HV systems. Such energy value was chosen as the absorbed energy slightly lower than the energy at the load peak for the C-LV-PB system (Fig. 3B). Impacted samples were analyzed with microCT to enlighten the way in which fibres work during the impact. The peak load reached during the impact event was higher in the noncompatibilized laminate (7501 N for C-HV versus $6407 \mathrm{~N}$ for C-HV-PB), and the absorbed energy was lower (17.9 J for C-HV versus $19.1 \mathrm{~J}$ for CHV-PB). This means that the not-compatibilized composite underwent lower damages with respect to the compatibilized one, and its fibres were able to bear a higher load. This is confirmed by the recovered energy value, which was higher in C-HV sample ( $8.0 \mathrm{~J}$ versus $9.2 \mathrm{~J}$ ) thus indicating more elastic energy stored in the not-compatibilized structure.

Table 3

Main impact parameters evaluated from falling dart impact tests $E_{a}-$ absorbed energy, $E_{r}$ - recovered energy, $E_{p e r f}-$ Absorbed energy after perforation, $E_{l p}$ Absorbed energy at load peak, $E_{a p}$ Absorbed energy after load peak, $\Delta E_{1 p}$ Variation of the absorbed energy at load peak between not compatibilized and compatibilized samples, $\Delta \mathrm{E}_{\mathrm{a}}$ Variation of the absorbed energy between not compatibilized and compatibilized samples).

\begin{tabular}{|c|c|c|c|c|c|c|c|c|c|}
\hline \multirow[t]{2}{*}{ Impact Energy } & \multicolumn{3}{|l|}{$27 J$} & \multicolumn{6}{|l|}{$105 \mathrm{~J}$} \\
\hline & Load peak (N) & $E_{a}(J)$ & $E_{r}(J)$ & $E_{\text {perf }}(J)$ & $E_{l p}(J)$ & $E_{a p}(J)$ & $\Delta E_{l p}$ & $\Delta E_{a}$ & Load Peak (N) \\
\hline C-LV & & & & $57.07 \pm 3.12$ & $36.75 \pm 1.27$ & $20.32 \pm 1.06$ & $28 \%$ & $16 \%$ & $9734 \pm 237$ \\
\hline C-LV-PB & & & & $48.99 \pm 2.46$ & $28.76 \pm 1.33$ & $20.23 \pm 0.82$ & & & $8554 \pm 183$ \\
\hline $\mathrm{C}-\mathrm{HV}$ & $7501 \pm 113$ & $17.9 \pm 0.8$ & $9.2 \pm 0.5$ & $69.42 \pm 2.84$ & $49.5 \pm 1.96$ & $19.92 \pm 1.18$ & $140 \%$ & $40 \%$ & $13217 \pm 279$ \\
\hline C-HV-PB & $6407 \pm 139$ & $19.1 \pm 0.6$ & $8.0 \pm 0.3$ & $49.55 \pm 2.13$ & $20.66 \pm 0.84$ & $28.89 \pm 0.94$ & & & $7497 \pm 151$ \\
\hline
\end{tabular}



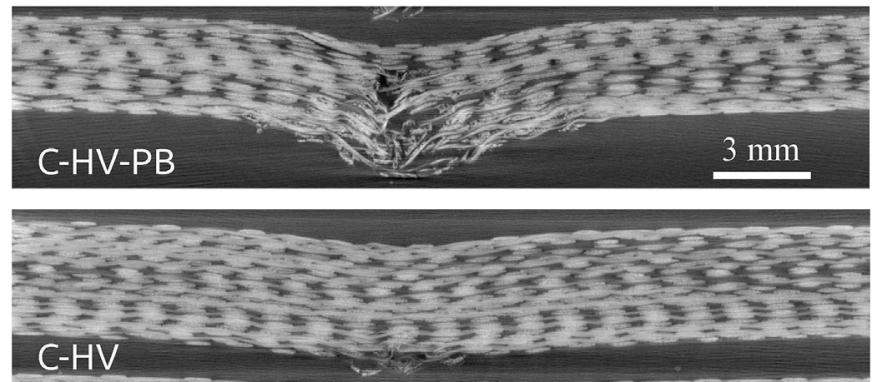

Fig. 4. Comparison of laminate sections of C-HV and C-HV-PB samples after the falling dart impact at $27 \mathrm{~J}$.

Fig. 4 shows the comparison of microCT acquisitions from C-HV and C-HV-PB samples. It is clear that in C-HV-PB the fibres were fractured through most part of the sample (only the top 4 fabric layers are not broken). Conversely, C-HV shows damaged fibres only in the lower part of the sample (back face) and only 4 or 5 fabric layers appear to be broken. The fabric layers along most of the thickness in the not-compatibilized sample are still in perfect working condition after the impact at $27 \mathrm{~J}$, leaving room for bearing higher loads before complete failure. This is confirmed by the load peak at perforation, which is $76 \%$ higher than the load peak measured under the $27 \mathrm{~J}$ impact in C-HV. On the contrary, the compatibilized laminate showed a load peak at perforation only $17 \%$ higher than the maximum load under the $27 \mathrm{~J}$ impact. The capability of fibres to slip in a not compatibilized matrix, guaranteed by the low adhesion energy between fibres and polymer, allows for a continuous optimized reallocation of the stress undergone by the laminate on the fibres without incurring in their fracture and keeping low the induced damages until very large deformations or ultimate stresses of reinforcing fibres are reached.

\subsection{Impact characterization - in-plane impacts}

Fig. 5 shows the typical impact curves from the Charpy tests. All curves show a first very quick spike event, characterized by a load peak at $300 \mathrm{~N}$. This was due to inertial effects related to the mechanical wave propagation through the thick samples. This peak was not considered as a laminate failure and was neglected since the following shape of the curve in all samples is perfectly straight up to much higher loads. Just like in the curve from falling dart impact tests, also in the case of inplane impacts the initial slope of the curves is in direct proportion with the stiffness of the laminates but, differently from out-of-plane impacts,

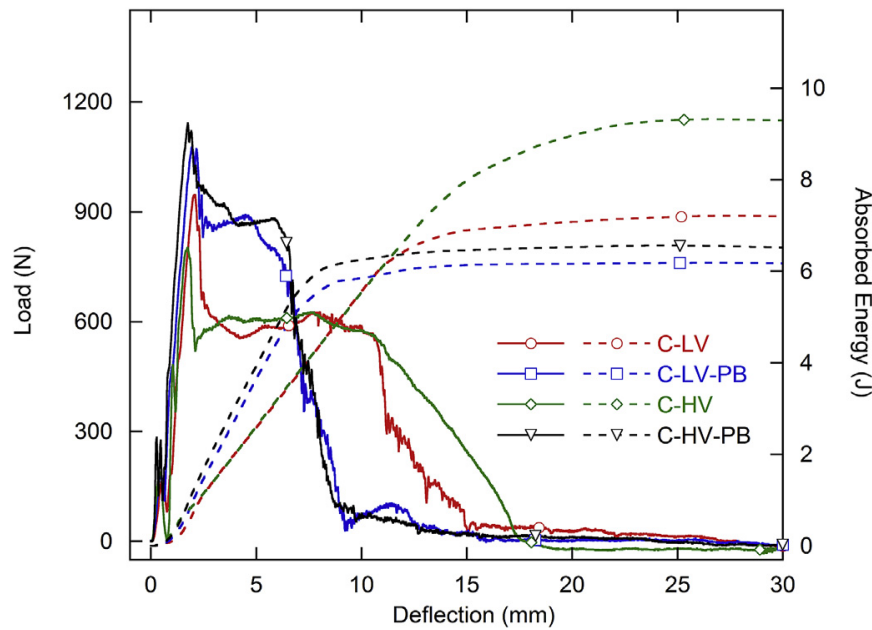

Fig. 5. Load-Deflection and Absorbed Energy-Deflection curves from Charpy tests.

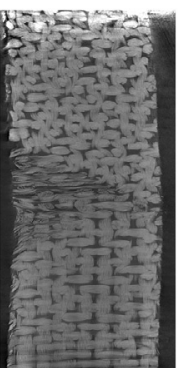

C-LV
C-LV-PB

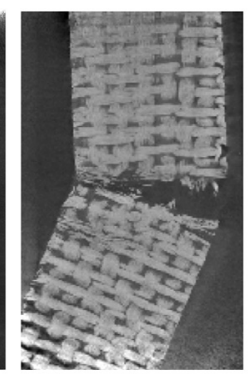

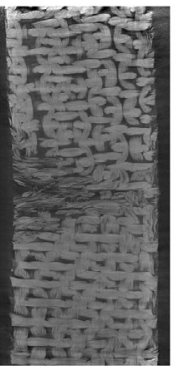

$\mathrm{C}-\mathrm{HV}$

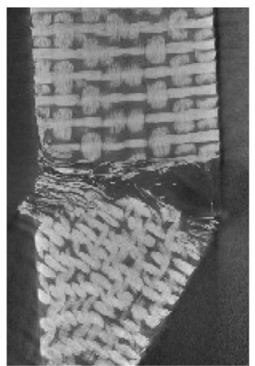

C-HV-PB
Fig. 6. Representative MicroCT micrographs along $\mathrm{z}$ direction of the different laminates.

also the load peak is in direct proportion with the static mechanical performance. The highest load peak was detected for C-HV-PB, followed by C-LV-PB, C-LV and finally C-HV. Also the absorbed energy at load peak is higher for compatibilized systems. The load after peak has a sharp drop and then it stays almost constant, showing a sort of plateau extending over a deflection range variable with the actual interface strength: the higher is the interface strength, the more extended is the plateau deflection range. Compatibilized specimens suddenly fail for deflections higher than $6.5 \mathrm{~mm}$, as a consequence of the catastrophic and passing fracture through the laminate width triggered by the failure of the back face of the sample. In not compatibilized samples such phenomenon does not occur, and the laminate tends to crush under the load without any catastrophic breaking of fibres (Fig. 6).

Table 4 reports the main parameters calculated from Charpy tests. The elastic energy stored in the laminate (i.e. up to the load peak) is lower than $1 \mathrm{~J}$ in all systems $\left(\mathrm{E}_{\mathrm{a}, \mathrm{Fmax}}\right)$, but compatibilized samples showed the highest values. On the contrary, the energy after load peak is clearly higher in not-compatibilized composites, as well as the total dissipated energy $\left(E_{a, b r}\right)$. This is due to the fact that after the load peak the compatibilized composites incur in matrix and fibre breakage that lead to the fracture propagation through the entire laminate, while the capability of not-compatibilized configurations to avoid fracture propagation between matrix and fibres and the slipping of fibres allow larger deformations and higher energy dissipation. It is worth to note that, unlike compatibilized systems, not-compatibilized laminates did not completely break after the Charpy impact test and, although crushed and without the original shape, they appear as having large part of fibres still not broken. This could imply that a not compatibilized laminate can bear higher in-plane loads, and is able to dissipate additional impact energy before its failure.

Tomographs of composites after Charpy impact tests are shown in Figs. 6-8, where representative slices taken along the three main axis are reported. Fig. 6 represents sections of the plane parallel to the impact direction, with the impact point on the left. A clear difference arise from the damage comparison of compatibilized and not compatibilized samples. Compatibilized samples (C-LV-PB and C-HV-PB) showed a) an almost complete fracture passing through the specimen width and iniziated on the back side, and b) a residual zone of crushed fibres close to the impact point. On the contrary, not compatibilized samples (C-LV and C-HV) exhibited a very large region of crushed fibres. The different behaviour can be related to the adhesion strength between fibres and matrix, which induces different dissipative mechanisms. The influence

Table 4

Main impact parameters evaluated from Charpy impacts.

\begin{tabular}{llll}
\hline & $E_{a, F \max }(J)$ & $E_{a, b r}(J)$ & $F_{\max }(N)$ \\
\hline C - LV & $956 \pm 41$ & $0.72 \pm 0.06$ & $7.49 \pm 0.89$ \\
C - LV - PB & $1033 \pm 40$ & $0.96 \pm 0.12$ & $5.78 \pm 0.13$ \\
C - HV & $795 \pm 46$ & $0.52 \pm 0.06$ & $8.86 \pm 1.44$ \\
C - HV - PB & $1158 \pm 38$ & $0.89 \pm 0.91$ & $6.13 \pm 0.09$ \\
\hline
\end{tabular}




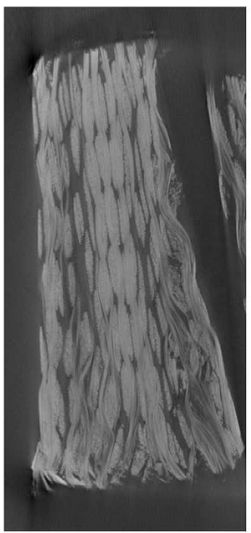

C-LV

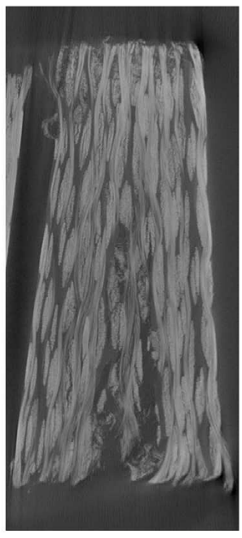

C-HV
Fig. 7. Representative MicroCT micrographs along $\mathrm{x}$ direction of the different laminates.

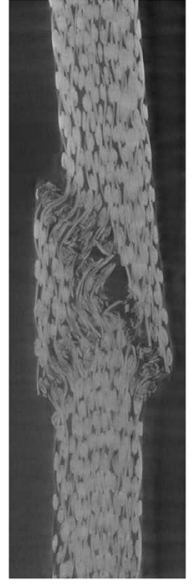

C-LV

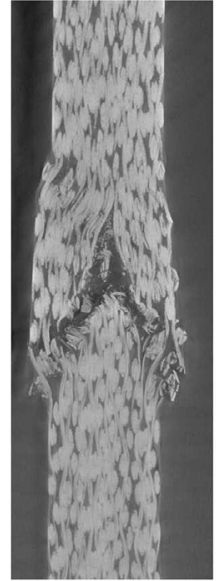

C-LV-PB

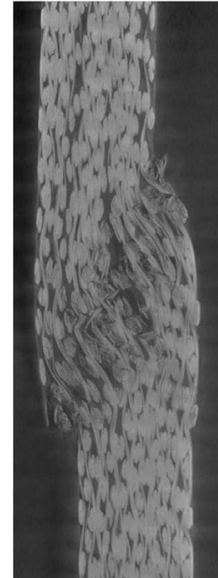

C-HV

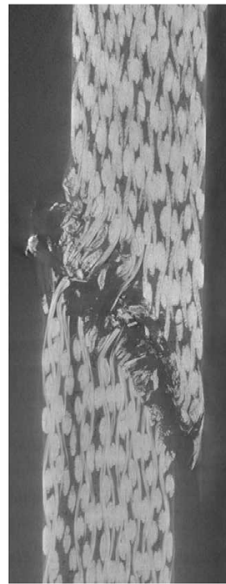

C-HV-PB
Fig. 8. Representative MicroCT micrographs along y direction of the different laminates.

of the fibre-matrix interfacial adhesion on the failure mode and, more in general, on the mechanical behaviour of composites has been the subject of many researches already available in the literature [24-26]. All the researchers agree with the consideration that the main failure mode changes from the interface failure interfacial adhesion to matrix fracture by enhancing the interfacial adhesion. Pisanova et al. [27] investigating the adhesion of carbon and glass fibers to thermoplastic matrices put in evidence that the interfacial bonding largely affects the failure mode. In particular, in the case of poor fibre matrix adhesion, interfacial failure (debonding) occurs whereas an increase of the interfacial adhesion favors the cracking of the matrix perpendicularly to the fibre and trigger its propagation.

During the Charpy impact, fibres close to the impact point are loaded in compression (both parallel and orthogonal to the impact direction) while fibres are loaded in tension on the opposite side of the sample (back side). The straight and neat fracture in compatibilized samples suggests a quick crack propagation, initiated on the back side by the fracture of, most likely, the matrix. A strong adhesion between fibres and matrix implies that a potential local failure (originated by a defect or a stress exceeding the local tension strength) is easily propagated between the two phases because there isn't any energy dissipation mechanism available that limits the crack growth. Conversely, a low adhesion between fibres and matrix allows multiple energy dissipation mechanisms occurring at lower stresses with respect to the fibre

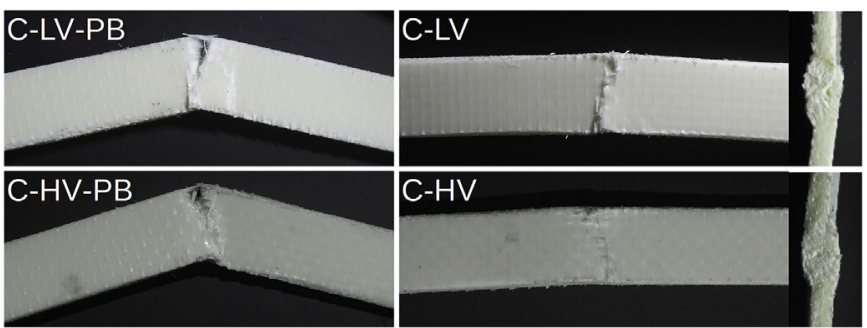

Fig. 9. Pictures of representative samples after Charpy test. On the right a picture representing the frontal, impacted zone in not compatibilized samples.

strength, such as fibre slipping with associated friction, delamination, spreading of the zone involved in the energy dissipation (wider volume of the sample reports damages). Any potential crack triggered by a defect or matrix failure on the tension loaded side is stopped and cannot propagate to the fibres, which in turn are able to withstand higher loads. A direct consequence is that the laminate fails in compression (in agreement with the results coming from static flexural tests), and a large "V" shaped crushed area is developed (clearly visible in not compatibilized samples in Figs. 6-8).

The reduced fibre/matrix adhesion allowed energy dissipation at large distances from the impact plane. Fig. 7 shows two slices taken at $7 \mathrm{~mm}$ from the impact point, where delaminations and crushed fibres are clearly visible. Such damages are also visible orthogonally to the impact direction in Fig. 8. Such types of damage are completely absent in compatibilized samples, and no damage was detected at $7 \mathrm{~mm}$ away from the fractured zone. It is worth to note that not-compatibilized laminates showed the capability to almost recover the deformation induced by the pendulum during the impact, while compatibilized composites showed a permanent change in the specimen shape (Fig. 9).

The comparison of out-of-plane and in-plane results shows that a) the contribution of the interface adhesion is dependent on the different direction of the impact load with respect to the fibre positioning, and $b$ ) compatibilized systems are very sensitive to the formation and propagation of cracks, because the laminates don't have any mechanism to limit them. In fact, the strengthening effect of fibres (and hence the capability of the laminate to bear loads) is present until delaminations occur, or fibres as well as matrix cracks initiate and propagate through the laminate thickness. In out-of-plane impacts the load is orthogonal to the reinforcing fabric layers, bound by the polymer in an alternate sequence of matrix and reinforcement, while in in-plane impacts the load is applied parallel to the reinforcing layers. In the latter case fibres can contribute to a larger extent to the impact response of the laminate and the crack propagation occurs at higher loads with respect to the out-ofplane case, where the laminate failure occurs at an early stage. The higher dissipated energy in not-compatibilized composites is due to the reduced adhesion between fibres and polymer, which allows for a larger number of dissipative phenomena with respect to compatibilized systems and to the spreading of the load through a much larger volume of the structure.

\section{Conclusions}

Out-of-plane and in-plane impact properties of PP/glass fibre fabric composites were investigated and compared. The role of the interface strength was analysed and related to the ultimate performance of the composites. The use of the compatibilizer in the composites resulted in improved flexural modulus and, to a significantly higher extent, flexural strength with more pronounced effects in the case of composites involving the matrix with higher viscosity (C-HV-PB). The lower flexural strength in not-compatibilized systems is due to the lower capability to transfer load from the polymeric matrix to the reinforcement.

As far as the impact behaviour is concerned, instead, a strong adhesion between matrix and fibres resulted in a reduction of the impact 
resistance, in particular for the C-HV-PB systems. The weak interface allows for additional dissipative mechanisms in both matrix and fibres, and limit the sensitivity to crack formation and propagation of the laminate. Fibre pull out, fibre slippage, and friction between fibres and matrix add to fibre breakage and delamination in dissipating the impact energy. All these phenomena impart to not compatibilized composites the capability to allow local rearrangement of the fibres (thanks to fibre slipping) and result in both spreading the load in a larger volume and stopping the damage propagation at the matrix/fibres interface. All the combined mechanisms contribute to increase the overall impact resistance. This behaviour detected in falling dart impact tests, which clearly showed how the reduced interface strength between fibres and matrix had a primary role in increasing the impact strength and preserved the integrity of fibres allowing much higher loads before laminate failure. It also verified in Charpy impact tests, in which compatibilized systems showed a higher load peak during the impact but failed for the propagation of a fracture through the laminate width. Not compatibilized systems, on the contrary, responded to the impact with fibre crushing and the spreading of the impact zone without failing. Furthermore, not-compatibilized systems showed the capability to preserve fibres and absorb more energy avoiding catastrophic fracture propagation through the laminate after the damage initiation.

\section{References}

[1] Stewart R. Thermoplastic composites - recyclable and fast to process. Reinforc Plast 2011;55:22-8.

[2] Yang Y, Boom R, Irion B, et al. Recycling of composite materials. Chem Eng Process Process Intensif 2012;51:53-68.

[3] Zarei H, Kröger M, Albertsen $\mathrm{H}$. An experimental and numerical crashworthiness investigation of thermoplastic composite crash boxes. Compos Struct 2008;85:245-57.

[4] Robert M, Roy R, Benmokrane B. Environmental effects on glass fiber reinforced polypropylene thermoplastic composite laminate for structural applications. Polym Compos 2010;31:604-11.

[5] Reis PNB, Ferreira JAM, Richardson MOW. Fatigue damage characterization by NDT in polypropylene/glass fibre composites. Appl Compos Mater 2011;18:409-19.

[6] Mulle M, Wafai H, Yudhanto A, et al. Process monitoring of glass reinforced polypropylene laminates using fiber Bragg gratings. Compos Sci Technol 2016;123:143-50.

[7] Russo P, Simeoli G, Sorrentino L, et al. Effect of the compatibilizer content on the quasi-static and low velocity impact responses of glass woven fabric/polypropylene composites. Polym Compos 2016;37:2452-9.

[8] Russo P, Acierno D, Simeoli G, et al. Flexural and impact response of woven glass fiber fabric/polypropylene composites. Compos B Eng 2013;54:415-21.
[9] Simeoli G, Acierno D, Meola C, et al. The role of interface strength on the low velocity impact behaviour of PP/glass fibre laminates. Compos B Eng 2014;62:88-96.

[10] Boccardi S, Meola C, Carlomagno GM, et al. Effects of interface strength gradation on impact damage mechanisms in polypropylene/woven glass fabric composites. Compos B Eng 2016;90:179-87.

[11] Sorrentino L, Simeoli G, Iannace S, et al. Mechanical performance optimization through interface strength gradation in PP/glass fibre reinforced composites. Compos B Eng 2015;76:201-8.

[12] Agrawal S, Singh KK, Sarkar P. Impact damage on fibre-reinforced polymer matrix composite - a review. J Compos Mater 2014;48:317-32.

[13] Hufenbach W, Ibraim FM, Langkamp A, et al. Charpy impact tests on composite structures - an experimental and numerical investigation. Compos Sci Technol 2008;68:2391-400.

[14] Russo P, Simeoli G, Acierno D, et al. Mechanical properties of virgin and recycled polyolefin-based composite laminates reinforced with jute fabric. Polym Compos 2015;36:2022-9.

[15] Rahman NA, Hassan A, Yahya R, et al. Impact properties of glass-fiber/polypropylene composites: the influence of fiber loading, specimen geometry and test temperature. Fibers Polym 2013;14:1877-85.

[16] Chai GB, Manikandan P. Low velocity impact response of fibre-metal laminates - a review. Compos Struct 2014;107:363-81.

[17] Aktaș M, Atas C, İçten BM, et al. An experimental investigation of the impact response of composite laminates. Compos Struct 2009;87:307-13.

[18] Mouti Z, Westwood K, Kayvantash K, et al. Low velocity impact behavior of glass filled fiber-reinforced thermoplastic engine components. Materials (Basel) 2010;3:2463-73.

[19] Yu B, Bradley RS, Soutis C, et al. 2D and 3D imaging of fatigue failure mechanisms of 3D woven composites. Composer Part A Appl Sci Manuf 2015;77:37-49.

[20] Quan Z, Larimore Z, Qin X, et al. Microstructural characterization of additively manufactured multi-directional preforms and composites via X-ray micro-computed tomography. Compos Sci Technol 2016;131:48-60.

[21] Schilling PJ, Karedla BR, Tatiparthi AK, et al. X-ray computed microtomography of internal damage in fiber reinforced polymer matrix composites. Compos Sci Technol 2005;65:2071-8.

[22] Sorrentino L, Sarasini F, Tirillò J, et al. Damage tolerance assessment of the interface strength gradation in thermoplastic composites. Compos B Eng 2017;113:111-22.

[23] Thomason JL. Micromechanical parameters from macromechanical measurements on glass reinforced polypropylene. Compos Sci Technol 2002;62:1455-68.

[24] Lee N-J, Jang J. The use of a mixed coupling agent system to improve the performance of polypropylene-based composites reinforced with short-glass-fibre mat. Compos Sci Technol 1998;57:1559-69.

[25] Zhandarov S, Mäder E. Characterization of fiber/matrix interface strength: applicability of different tests, approaches and parameters. Compos Sci Technol 2005;65:149-60.

[26] Yang L, Thomason JL. Development and application of micromechanical techniques for characterising interfacial shear strength in fibre-thermoplastic composites. Polym Test 2012;31:895-903.

[27] Pisanova EV, Zhandarov SF, Dovgyalo VA. Interfacial adhesion and failure modes in single filament thermoplastic composites. Polym Compos 1994;15:147-55. 